2006-1779: A GUIDING VISION, ROAD MAP, AND PRINCIPLES FOR RESEARCHING AND TEACHING SUSTAINABLE DESIGN AND CONSTRUCTION

Karen Hansen, California State University-Sacramento

Assistant Professor

Jorge Vanegas, Georgia Institute of Technology 


\title{
A Guiding Vision, Road Map, and Principles for Researching and Teaching Sustainable Design and Construction
}

\begin{abstract}
The Architecture, Engineering, and Construction $(\mathrm{A} / \mathrm{E} / \mathrm{C})$ industry plays a critical role in delivering a diverse range of Facilities and Civil Infrastructure Systems (F\&CIS), including residential, building, industrial facilities, and transportation, energy, water supply, waste management, and communications systems. It also plays a critical role in maintaining their quality, integrity, and longevity. At the same time, the $\mathrm{A} / \mathrm{E} / \mathrm{C}$ industry contributes to natural resource depletion, waste generation and accumulation, and environmental impact and degradation. Traditional approaches of environmental regulatory compliance, or of reactive corrective actions to slow, reduce, and eliminate these impacts have proven to be consistently costly, inefficient and often ineffective. In response, a wide range of constituencies from both within and outside the $\mathrm{A} / \mathrm{E} / \mathrm{C}$ industry have been attempting to define the attributes and characteristics of sustainable F\&CIS, the processes for the sustainable delivery and use of F\&CIS, and the resources required for the delivery and use of F\&CIS in a sustainable way.

In a sustainable approach to F\&CIS, decision-makers need to integrate sustainability at all stages of the project life cycle, particularly the early funding allocation, planning and conceptual design phases. More specifically, to be successful in the pursuit of sustainability, the $\mathrm{A} / \mathrm{E} / \mathrm{C}$ industry needs to: (1) define, plan, and design more sustainable F\&CIS; (2) procure, construct, commission, operate, and maintain F\&CIS in more sustainable ways; and (3) supply more sustainable building technologies, systems, products and materials used within F\&CIS. Satisfying these needs require a new paradigm, anchored in three elements: the first is a vision for sustainability at global, industry, and project levels; the second is an implementation road map at strategic, tactical, and operational levels; and the third is a set of specific sustainability principles, which provide the foundation for the vision and road map.
\end{abstract}

The challenges posed by this paradigm are, among others: (1) sustainability is a very complex domain; (2) the literature on built environment sustainability is rich, extensive, and diverse; and (3) many academic institutions have active and mature education and research programs on built environment sustainability that have evolved over years of work and with a significant amount of sponsored research investment. So the questions for educators and researchers who may be interested in establishing education and research programs in sustainable F\&CIS are: What can be done? How can it be done? With what resources can it be done? This paper proposes answers to these three questions, as a starting point for an on going, industry-wide dialogue.

\section{Introduction}

According to the Brundtland Commission, the concept of sustainable development is a way to ensure "...meeting the needs of the present without compromising the ability of future generations to meet their own needs." [1] Other authors, such as Liverman et al., go beyond this definition, and define "....sustainability to be the indefinite survival of the human species (with a quality of life beyond mere biological survival) through the maintenance of basic life support systems (air, water, land, biota) and the existence of infrastructure and institutions which distribute and protect the components of these systems." [2]

Multiple organizations within the international community have been formally, explicitly, and proactively addressing sustainable development and sustainability for many years, for example: the World Business Council for Sustainable Development (WBCSD), the World Federation of Engineering Organizations (WFEO), the World Bank, the United Nations, Lead International, and numerous Non-Governmental Organizations (NGOs). Examples in the U.S. include, among others: 
(1) organizations in the private and public sectors, ranging from corporate members of the Business Roundtable, and numerous professional and trade associations, through multiple Federal, State, Local Government Agencies, and the Military Services, to Non-Governmental Organizations (NGOs) and civic activist groups; (2) practitioners from the agricultural, manufacturing, and Architecture, Engineering, and Construction $(\mathrm{A} / \mathrm{E} / \mathrm{C})$ industry; (3) researchers, and educators in the physical, life, and social sciences, and in the many disciplines of engineering, architecture, city planning, and others; and (4) individuals, families, and communities, in urban, suburban, and rural settings.

Although the convergence of this diverse set of constituencies around sustainability is very positive, the wide diversity and range of perspectives among them has generated numerous definitions, conceptualizations, and frameworks of sustainability, with some of them compatible, and some of them in conflict, with each other. [3] In addition, the magnitude and scope of the existing and evolving body of knowledge on sustainable development and sustainability are daunting. Furthermore, an examination of this body of knowledge also reveals that there is no unified theory of sustainability, and sustainability is addressed in multiple forms such as principles, concepts, heuristics, strategies, guidelines, specifications, standards, processes, tools, best practices, lessons learned, and case studies. However, within this diversity and complexity, there is one area of consensus: The status quo is not sustainable in the long term. Individuals, communities, and organizations must invest in the development and the implementation of alternative, innovative, and more sustainable strategies, tactics, and mechanisms because they cannot continue indefinitely as they have in the past, (1) doing what they do, i.e., products, goods, or services; (2) operating how they do i.e., processes, practices, and procedures; and (3) using what they use, i.e., the resources required - natural, social, and economic capital.

More specifically within the $\mathrm{A} / \mathrm{E} / \mathrm{C}$ industry, the literature on built environment sustainability is rich, extensive, and diverse. A parametric review of existing literature in this area [4] identified general references (e.g., [5], [6], and [7]); models and frameworks (e.g., [8], [9], and [10]); heuristics and guidelines (e.g., [11], [12], and [13]); assessment and evaluation tools, (e.g., [14], [15], and [16]); and resource guides (e.g., [17], [18], and [19]). However, the unique attributes and characteristics of F\&CIS, the complexities of the current processes for their delivery and use, and the diverse set of resources required for both their delivery and use (e.g., labor, equipment, materials, technologies, money, and energy, among others), make the implementation of built environment sustainability a difficult goal. Consequently, there is a need to develop answers to the following questions:

$\circ$ How can the $\mathrm{A} / \mathrm{E} / \mathrm{C}$ industry define, plan, and design more sustainable F\&CIS?

$\circ$ How can the $\mathrm{A} / \mathrm{E} / \mathrm{C}$ industry procure, construct, commission, operate, and maintain F\&CIS in more sustainable ways?

- How can the $\mathrm{A} / \mathrm{E} / \mathrm{C}$ industry supply more sustainable building technologies, systems, products and materials used within F\&CIS?

Providing answers to these questions is driving educators and researchers to establish education and research programs in sustainable F\&CIS. However, given that sustainability is a very complex domain, that the literature on built environment sustainability is extensive and diverse, and that many academic institutions have active and mature education and research programs on built environment sustainability that have evolved over many years of work, with a significant amount of sponsored research investment, educators and researchers face three challenges:

- What can educators and researchers in any discipline related to the built environment (Architecture, Engineering, and Construction, and others) do to establish new education and research programs in sustainable F\&CIS?

- How can they do it?

$\circ \quad$ What resources will they need?

This paper proposes an initial set of answers to these three questions as a starting point for an ongoing, industry-wide dialogue. The overarching goal is to offer a mechanism for the transfer of 
knowledge and experience from an established education and research program in built environment sustainability to one that is just starting, in order to avoid a duplication of the research investment already made, to lessen the time it takes to get a launch a program from the very beginning, and to capitalize on lessons learned.

The point of departure for establishing new education and research programs in sustainable F\&CIS is an understanding of a new paradigm for built environment sustainability. This paradigm is anchored in three elements: the first is a vision for sustainability at global, industry, and project levels; the second is an implementation road map at strategic, tactical, and operational levels; and the third is a set of specific sustainability principles, which provide the foundation for the vision and the road map. More details on these three elements, which are described next, can be found in [20].

\section{A Vision for Built Environment Sustainability}

A vision for Built Environment Sustainability (BES) has three levels: a global level, an industry level, and a project level visions. At each level, there are questions that could be answered through research, problems and needs that could be solved and satisfied through design and construction, opportunities that could be realized through entrepreneurship, and aspirations that can be fulfilled through practice, outreach, service, education, and/or research. The full vision for BES offers an initial cornerstone for the establishment and implementation of an active and integrated education and research program in sustainable F\&CIS.

Global Level Vision - A global level vision of BES calls for the implementation of mechanisms to transform the traditional linear development process followed by the $\mathrm{A} / \mathrm{E} / \mathrm{C}$ industry, which uses energy, depletes and degrades the resource base, generates and accumulates waste, and negatively impacts and degrades the environment, into a sustainable closed cyclical system framed within a global context. This sustainable system contains several characteristics that are key to achieving sustainability:

- The system is framed within a context defined by specific social, cultural, political, and regulatory, the economic and financial, and the ecological and environmental systems.

- Intra- and intergenerational satisfaction of human needs and aspirations are an integral part of the outcomes of the development process.

- Natural resource use is managed proactively through monitoring and control of the extraction of resources from the biosphere in a way that ensures that the supply will always exceed the demand, and of the extraction of nonrenewable natural resources from the lithosphere to prevent their total depletion.

- Sustainable strategies and technologies are used proactively within every element of the system:

- To promote the development, and to enable the use, of environmentally conscious alternatives and substitutes to current resources and energy sources used;

- To prevent or mitigate environmental impacts before any damage to the environment occurs, such as preservation, pollution prevention, avoidance, monitoring, and technologies for assessment and control; and

- To correct environmental impacts when some damage to the environment already has been done, such as remediation or restoration technologies.

- Recovery of selected resources and products is actively pursued within every element of the system, through direct reuse of reusable components, remanufacture of reusable elements, reprocessing of recycled materials, and monomer/raw material generation.

- The system is on a gradual and continuous move towards sustainability.

Industry Level Vision - An industry level vision of BES calls for the implementation of mechanisms to turn the $\mathrm{A} / \mathrm{E} / \mathrm{C}$ industry into a collaborative pull/push business environment among three distinct groups of stakeholders: those involved within the total life cycle of the delivery and use of facilities; 
those involved within the total life cycle of the delivery and use of civil infrastructure systems; and those involved within the total life cycle of the delivery and use of technologies, systems, products, materials, and equipment, have a collaborative interaction with each other. BES requires a collaborative pull/push business environment, within which each of these stakeholders can either pull or push the others toward the development of sustainable facilities, of sustainable civil infrastructure systems, and of sustainable technologies, systems, products, materials, and equipment.

Project Level Vision - A project level vision of BES encompasses a complete life cycle perspective, focused on the evaluation of outcomes of using a delivered facility or civil infrastructure system for the project originator. $\mathrm{A} / \mathrm{E} / \mathrm{C}$ projects begin as response to a specific problem, a need, an opportunity, or an aspiration from an enterprise, an organizational unit or a functional unit within an enterprise, or from an individual. They continue with definition and delivery processes focused on the efficiency and productivity of (1) the management of the planning, the design, the procurement and construction, and the commissioning and start-up processes; and (2) the management and use of the resource base. Resources can include economic and financial resources; physical resources such as materials, equipment, and tools; human resources such as technical, non-technical, and administrative personnel; technological resources, such as computing, communication, collaboration, and management of information technologies; and miscellaneous other resources such as data/information, knowledge/experience abilities/skills, technological proficiency. The project ends with the delivery of a completed facility or civil infrastructure system. For BES, the scope of an A/E/c project needs to expand to:

- Address $\mathrm{A} / \mathrm{E} / \mathrm{C}$ projects from their complete life cycle perspective, including operations and maintenance, and also the end-of-service life decision

- Emphasize the use of sustainable resources

- Monitor and document the outcomes resulting from the use of the facility or civil infrastructure system delivered

- Provide a post-occupancy evaluation and feedback to the project originator that, depending on what the project driver was, answers the question: Did the project delivered solve the problem? Satisfy the need? Capitalize on the opportunity? Realize the desire?

\section{An Implementation Roadmap for Built Environment Sustainability}

Although the vision discussed in the previous section provides an initial foundation for BES, it is not enough; further actions are required from an implementation perspective. Thus, achieving BES requires an implementation roadmap that includes three types of actions: strategic actions, tactical actions, and operational actions. As with the different levels of the vision proposed, within these three types of implementation actions there are questions, problems, needs, opportunities, and aspirations that can be fulfilled through design and construction practice, outreach, service, education, and/or research. The full implementation roadmap for BES offers a second cornerstone for the establishment and implementation of an active and integrated education and research program in sustainable F\&CIS. For a more detailed discussion on these implementation actions, see [20], [21], [22], and [23].

Strategic Implementation Actions - From a strategic perspective, enabling and achieving sustainable $\mathrm{F} \& \mathrm{CIS}$ requires framing an $\mathrm{A} / \mathrm{E} / \mathrm{C}$ project within a contextual envelope defined by three axes: the " $\mathrm{x}$ " axis represents requirements and characteristics of the specific facility or civil infrastructure system; the " $y$ ' axis represents the processes followed in its delivery and use; and the " $\mathrm{z}$ " axis represents the resources consumed in its delivery and use. Each of these axes represents a relative scale that spans from what is unsustainable to what is sustainable in each one, with the thresholds that separate the two extremes within each axis as point $(0,0,0)$. The strategy is to use sustainability as a fundamental criterion in making decisions, choosing among various options, or taking actions, maintaining them within the octant where all three $(\mathrm{x}, \mathrm{y}, \mathrm{z})$ points are sustainable. While this may be conceptually simple, in reality it is quite complex, and much research is still required to provide clear and absolute definitions of what is sustainable, what is unsustainable, and what is the threshold that separates them. 


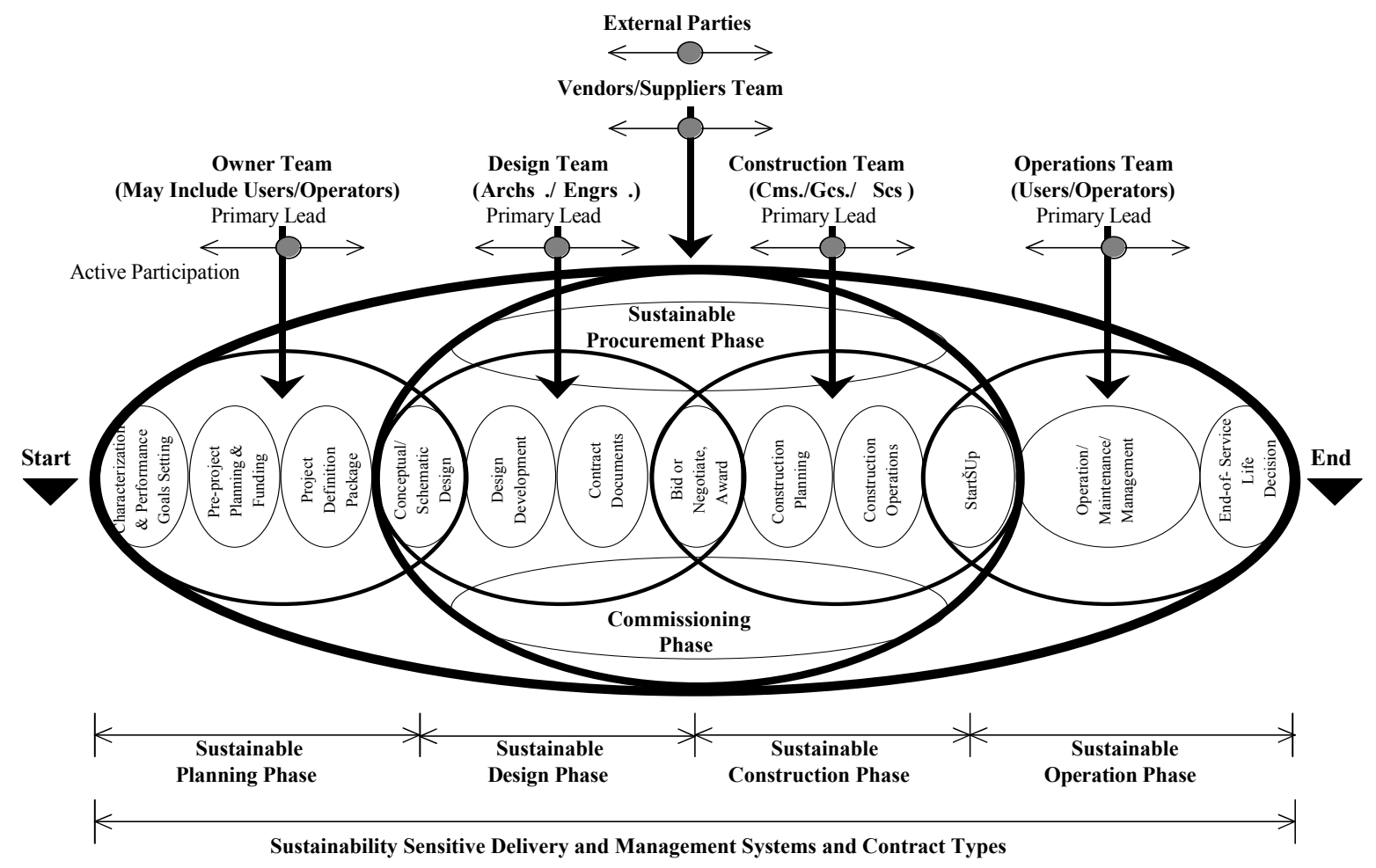

Figure 1. Tactical Level Implementation of Built Environment Sustainability

(Source [20])

Tactical Implementation Actions - From a tactical perspective, enabling and achieving sustainable F\&CIS requires ensuring that:

- The delivery and management systems for an $\mathrm{A} / \mathrm{E} / \mathrm{C}$ project are sensitive to sustainability and do not inhibit its implementation in any way.

- All project stakeholders (i.e., the Owner and Operations Team, the Design Team, the Construction Team, Vendor and Suppliers, and External Parties) have a common ground for understanding sustainability principles and concepts; operate as a high-performance team; and use sustainability as a fundamental criterion when making decisions, choosing among various options, or taking actions for the project at each stage of its life cycle.

- Any process, practice, or operating procedure followed within the various phases of the life cycle of an $\mathrm{A} / \mathrm{E} / \mathrm{C}$ project (i.e., the planning phase, the design phase, the construction, procurement, and commissioning phases, and the operations and maintenance phase), provides an entry point for formal and explicit input of sustainability in any of its manifestations. These phases are shown in Figure 1.

Each of these phases contributes in different ways to establish the degree, breadth, and depth of sustainability throughout an AEC project. At the same time, they offer an organizational structure for the implementation of an education and research program in sustainable F\&CIS. For example:

- Sustainable Planning has the greatest potential to influence overall project sustainability at lowest cost. Specific education and research opportunities in this phase can include investigating and teaching how to frame project requirements and characteristics within a sustainability perspective, how to select sustainable sites, and how to ensure the compatibility of project objectives and scope with the constraints of its physical and non-physical contexts. 
- Sustainable Design affords significant opportunities for influencing project sustainability before any construction operations begin on site. Specific education and research opportunities in this phase can include investigating and teaching how to develop sites in a sustainable way, how to design integrated building systems, how to achieve energy and water efficiency, how to develop and use sustainable materials, and how to achieve indoor environmental quality.

- Sustainable Procurement parallels the design and construction phases, and provides the interface with the supply chain that provides all the technologies, systems, products, materials, and equipment specified by designers to physically realize the project. Specific education and research opportunities in this phase can include investigating and teaching how to reduce or eliminate packaging, how to increase the recycled content in materials, how to minimize waste, and how to make manufacturer processes more environmentally benign.

- Sustainable Construction is the bridge between concept and reality, and offers additional opportunities for increasing sustainability of the project. Specific education and research opportunities in this phase can include investigating and teaching how to avoid site disturbance, how to promote construction recycling and resource reuse, and how to achieve health and safety.

- Commissioning is an important phase that ensures that all the building systems and equipment are installed and tested during construction to ensure their performance is within the parameters desired and specified. Specific education and research opportunities in this phase can include investigating and teaching how to reduce operations and maintenance costs, how to avoid inefficient energy and water use, and how to increase the productivity of people working in a facility.

- Sustainable Operations involves effective planning and allocation of resources over the operational life of the facility. Specific education and research opportunities in this phase can include investigating and teaching how to ensure indoor environmental quality, thermal comfort, and light quality, how to conserve energy, water, and resources, and how to manage waste. This phase also includes explicit consideration of what happens to the facility or civil infrastructure system at the end of its useful life of the facility. Additional education and research opportunities in this phase can include investigating and teaching how to disassemble and reuse building components, how to recover or recycle materials, and how to reclaim sites.

Operational Implementation Actions - From an operational perspective, enabling and achieving sustainable F\&CIS requires integrating sustainability within all the elements of project definition, as shown in Figure 2 on the following page. As with the phases of the life cycle of an A/E/C Project, each of these elements of project definition contributes in different ways to establish the degree, breadth, and depth of sustainability in the project. At the same time, they offer an organizational structure for the implementation of an education and research program in sustainable F\&CIS.

Specific education and research opportunities associated with each element of project definition can include investigating and teaching how to formally, explicitly, systemically, systematically, and proactively incorporate sustainability principles within:

- The Project Business Case and Plan, to ensure that sustainability is one of the drivers and desired outcomes for the project

- Site Selection, to ensure that the project site supports sustainable site development principles

- The Project Definition Package, to ensure that in the identification and documentation of the parameters of performance for the project, sustainability is addressed explicitly

- The analysis of the Physical and Non-physical Contexts of the Project, to ensure not only the analyses of geographical location, accessibility, transportation options, surface and subsurface conditions, environmental conditions, existing infrastructure, and surrounding activities or assets, but also the analyses of policy issues, legal and regulatory issues, applicable codes, standards, and regulations, economic and financial issues, political issues and public relations, community, social, and cultural issues, industrial, and technological issues 


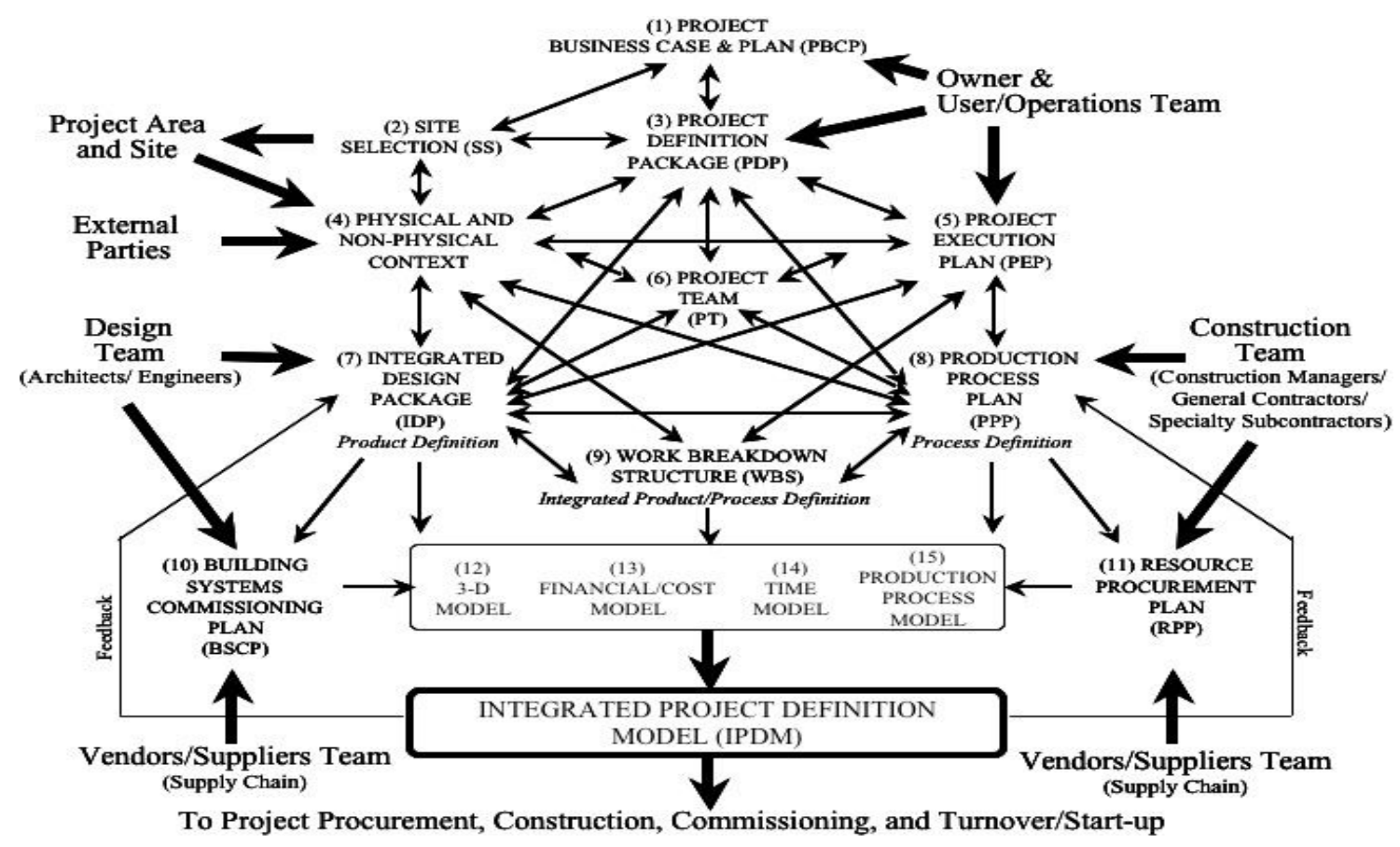

Figure 2. Operational Level Implementation of Built Environment Sustainability

(Developed from [20])

- The Project Execution Plan, to ensure that the delivery system and contract types used in the project are sensitive to, and support the implementation of sustainability

- Project Team Definition, to ensure that all the individuals, functional units, and organizations of the Project Team (from the Owner and User/Operator Teams, through the Design and Construction Teams, to the Vendors and Suppliers, and External Parties in the project) including all directly and indirectly involved in the project support the implementation of sustainability in the project

- The Integrated Design Package, to ensure that a sustainable design solution for the project that responds to each parameter of performance established in the project definition package, specifically:

- How the project services and supports the people who will use it, the activities and processes that will take place in it, and the inter-relationships among them

- How the project addresses the site layout and the spatial solution, and how they perform over time

- What the technologies, systems, products, materials, and equipment used in the project are, and how they perform over time

- How the project addresses ease of procurement, construction, and commissioning and start-up

- How the project addresses ease of operations, maintenance, and security

- How the project ensures the physical health and well-being of the people who will be the project's ultimate users, as a function of indoor air quality, potable water quality, emissions from materials (e.g., paints, carpets, adhesives), lighting, noise pollution, work environment, and comfort

- How the project eliminates, reduces, or mitigates any type of: Resource Base Impacts, i.e., resource consumption and waste generation; Eco-system Impacts, i.e., environmental impacts to air, water, soil, and biota; and Human Impacts, i.e., current and future impacts to all project stakeholders 
- The Production Process Plan, to ensure that the project follows sustainability principles, in the strategies for fabrication, supply, and delivery of all required technologies, systems, products, materials, and equipment; in their site installation, testing, and turnover; and in the overall logistics, workflow, and production unit control

- The Work Breakdown Structure (WBS), to ensure that sustainability is explicitly addressed within the various ways in which the work can be broken down in the project, especially from a product and process perspectives.

- The Project Commissioning Plan, to ensure the proper commissioning of all the building systems and equipment in the project

- The Project Procurement Plan, to ensure the procurement of sustainable resources for the project

- The 3D Model, to ensure that sustainable features of the project are properly reflected in the three-dimensional spatial data and information of the design solution of the project

- The Cost/Financial Model, to ensure that sustainable features of the project are properly reflected in the project's Total Installed Costs (TIC), the Operations \& Maintenance (O\&M) Costs, and the Life Cycle Costs (LCC)

- The Time Model, to ensure that sustainable features of the project are properly reflected in the cycle times of each of the phases of the life cycle of the project

- The Production Process Model, to ensure that sustainable features of the project are properly reflected in the production process to follow in the field during construction of the project

\section{Sustainability Principles}

Effective implementation and achievement of built environment sustainability begin with a vision for BES at global, industry, and project levels, and continue with a roadmap for implementation of BES at strategic, tactical, and operational levels. However, to fully achieve BES, what is required is the continuous application of specific sustainability principles, concepts, heuristics, strategies, guidelines, specifications, standards, processes, tools, best practices, lessons learned, or case studies within the various processes embedded in the vision and the implementation roadmap. Sustainability principles offer a third and final cornerstone for the establishment and implementation of an active and integrated education and research program in sustainable F\&CIS. They also offer an organizational structure for the implementation of an education and research program in sustainable F\&CIS.

Specific education and research opportunities exist within the extensive body of general knowledge on sustainability. For example, the International Institute for Sustainable Development provides an extensive compilation of sustainable development principles from numerous sources that address three major aspects: environment, economy and community. [24] In addition, and as mentioned previously, there is also an extensive body of specific knowledge on built environment sustainability. The key is to investigate how to adapt and customize this knowledge to the specific reality of an $\mathrm{A} / \mathrm{E} / \mathrm{C}$ project, and then establish the education and training programs to teach students and practitioners how to apply it. For example, some selected examples of principles that can be used to implement and achieve BES include:

- The Precautionary Principle, which guides human activities to prevent harm to the environment and to human health [25]

- The Earth Charter Principles, which promote respect and care for the community of life, ecological integrity, social and economic justice, and democracy, nonviolence, and peace [26]

- The Natural Step System Conditions, which define basic principles for maintaining essential ecological processes, and recognizing the importance of meeting human needs worldwide, as integral and essential elements of sustainability [27]

- The Daly Principles, which address the regenerative and assimilative capacities of natural capital, and the rate of depletion of non-renewable resources [28] 
- The Ceres Principles, which provide a code of environmental conduct for environmental, investor, and advocacy groups working together for a sustainable future [29]

- The Bellagio Principles, which serve as guidelines for starting and improving the sustainability assessment process and activities of community groups, non-government organizations, corporations, national governments, and international institutions, including the choice and design of indicators, their interpretation and communication of the result [30]

- The Ahwahnee Principles, which guide the planning and development of urban and suburban communities in a way that they will more successfully serve the needs of those who live and work within them [31]

- The Interface Steps To Sustainability, which were created to guide the Interface company in addressing the needs of society and the environment by developing a system of industrial production that decreases their costs and dramatically reduces the burdens placed upon living systems [32]

- The Hannover Principles, which assist planners, government officials, designers, and all involved in setting priorities for the built environment, and promoting an approach to design which may meet the needs and aspirations of the present without compromising the ability of the planet to sustain an equally supportive future [33]

- Design through the 12 Principles of Green Engineering, which provide a framework for scientists and engineers to engage in when designing new materials, products, processes, and systems that are benign to human health and the environment [34]

\section{Integrating Sustainability Principles into the Civil Engineering Education}

The most important thing to keep in mind when attempting to establish and implement an active and integrated education and research program in sustainable F\&CIS is that there is no need to start from the beginning. Experiences in academic institutions like the ones at the Georgia Institute of Technology (see [35] and [36]), can be shared with, transferred to, and adapted to academic institutions like California State University - Sacramento.

There are several approaches available to integrate sustainability principles into civil engineering education; however, the primary ingredient is the existence of a sustainability champion. Necessary for the implementation of any innovation, the champion fills the role of advocate. The sustainability champion may develop a specific course or courses that investigate sustainability principles. Courses on construction materials, professional civil engineering practice, and/or senior engineering design also may include modules that address sustainability principles.

Academic resources available to the sustainability champion include faculty members from other university departments and sustainability experts from other universities. At California State University - Sacramento, for example, faculty members from a variety of departments are uniting to form a Sustainability Center. Experts from other universities who have established programs also form a rich source of information and inspiration.

Industry resources available to the those wishing to integrate sustainability principles into the civil engineering curriculum include organizations such as the U.S. Green Building Council (USGBC), which has developed a Leadership in Energy and Environmental Design (LEED) certification program, the UK's Building Research Establishment (BRE), the American Society of Civil Engineers (ASCE), the American Institute of Architects (AIA), and the International Council for Building Research Studies and Documentation (CIB), among others. Additionally, journals such as Environmental Management, the International Journal of Environmental Technology and Management, Environmental Building News and numerous conferences provide vehicles for learning what others are doing currently and for publishing findings. 


\section{Conclusions}

This paper reflects one example of a partnership between the two co-authors to do so. As the journey progresses, insights gained, and lessons learned will be shared. The journey to BES is a long one, and improving the sustainability of F\&CIS can be achieved one decision, one choice, or one action at a time; one paradigm at a time; one product or one process at a time; phase by phase in the complete life cycle of an $\mathrm{A} / \mathrm{E} / \mathrm{C}$ project; one $\mathrm{A} / \mathrm{E} / \mathrm{C}$ program or one $\mathrm{A} / \mathrm{E} / \mathrm{C}$ project at a time; one $\mathrm{A} / \mathrm{E} / \mathrm{C}$ enterprise at a time; one $\mathrm{A} / \mathrm{E} / \mathrm{C}$ industry sector at a time; in a gradual shift to a sustainable future. More importantly, from an academic perspective, it can also be achieved one research project, and one course at a time.

\section{Bibliography}

[1] WCED - World Commission on Environment and Development (1987). Our Common Future. Oxford: Oxford University Press

[2] Liverman, D.M., Hanson, M.E., Brown, B.J., and Merideth, R.W., Jr. (1988). "Global Sustainability: Toward Measurement." Environmental Management, 12(2), 133-143

[3] Carpenter, S., and Vanegas, J. (1998) "Towards Sustainable Civil Infrastructure Systems," Proceedings of the Sustainable Technology and Complex Ecological and Social Systems Conference, of the fortysecond Annual Meeting of the International Society for the Systems Sciences, Atlanta, Georgia

[4] Pearce, Annie R. and Vanegas, Jorge A. (2002a). "A parametric review of the built environment sustainability literature," International Journal of Environmental Technology and Management, Inderscience Enterprises, Ltd., Volume 2, Nos. 1/2/3, 2002, pp. 54-93

[5] Langston and Ding (2001), op cit.

[6] Barnett, D.L., and Browning, W.D. (1995). A Primer on Sustainable Building, Rocky Mountain Institute, Snowmass, CO, USA

[7] Woolley, T., Kimmins, S., Harrison, P., and Harrison, R. (1997). Green Building Handbook, E. and F.N. Spon, New York, NY, USA

[8] Lyle, J.T. (1994). Regenerative Design for Sustainable Development, Wiley Press, New York, NY, USA

[9] CIB - International Council for Building Research Studies and Documentation (1998). Sustainable Development and the Future of Construction: A Comparison of Visions from Various Countries, CIB Publication 225, W82 - Future Studies in Construction, Rotterdam, The Netherlands

[10] Hill, R.C., Bergman, J.G., and Bowen, P.A. (1994). "A framework for the attainment of sustainable construction," in C.J. Kibert (Ed.), Proceedings of the First International Conference on Sustainable Construction, CIB TG 16, Tampa, FL, 6-9 November 1994

[11] EBN (1992). "Checklist for environmentally sustainable design and construction," Environmental Building News, Building Green, Inc., Brattleboro, VT, USA, Volume 1, Number 2, February 1992 (updated 2001)

[12] PTI - Public Technology, Inc. (1996). Sustainable Building Technical Manual: Green Building Design, Construction, and Operations, Public Technology, Inc., Washington, DC, USA

[13] Mendler, S.F., and Odell, W. (2000). The HOK Guidebook to Sustainable Design, John Wiley and Sons, New York, NY, USA

[14] Lippiatt, B.C., and Norris, G.A. (1995). "Selecting environmentally and economically balanced building materials," Proceedings of the $2^{\text {nd }}$. International Green Building Conference and Exposition - 1995, NIST SP 888

[15] Baldwin, R., Yates, A., Howard, N., and Rao, S. (1998). Building Research Establishment Environmental Assessment Method (BREEAM) 98 for Offices, Building Research Establishment, Construction research Communications, London, UK

[16] USGBC - U.S. Green Building Council (2000). "Leadership in energy and environmental design (LEED) green building rating system, Vol. 2.0," U.S. Green Building Council, Washington, DC, USA

[17] St. John, A. (1992). The Sourcebook for Sustainable Design, A Guide for Environmentally Responsible Building Materials and Processes, Boston Society of Architects, Boston, MA, USA

[18] Hermannsson, J. (1997). Green Building Resource Guide, Taunton Press, Newtown, CT, USA

[19] Holmes, D., Strain, L., Wilson, A., and Leibowitz, S. (1999). GreenSpec, The Environmental Building News Product Directory and Guideline Specifications, E-Build, Inc., Brattleboro, VT, USA

[20] Vanegas, Jorge A. (2003). "Road Map and Principles for Built Environment Sustainability," Environmental Science \& Technology. 2003, 37, 5363-5372

[21] Vanegas, J. (2001) "The Project Definition Package: A Cornerstone for Enhanced Capital Project Performance," Proceedings of the 2001 World Congress of the International Council for Research and 
Innovation in Building and Construction (CIB), Wellington, New Zealand (paper in conference CD ROM)

[22] Vanegas, J., and Pearce, A. (2000) "Drivers for Change: An Organizational Perspective on Sustainable Construction," Proceedings of the ASCE Construction Congress VI, American Society of Civil Engineers, Reston, Virginia, pp. 406-415

[23] Pearce, Annie R. and Vanegas, Jorge A. (1999). "Built Environment Sustainability: Indicators, Evaluation, and Decision Making,” Proceedings, Second Annual EDF Workshop on Excellence in Building, Paris, France.

[24] The International Institute for Sustainable Development Compilation of Sustainable Development Principle; available online at: http://www.iisd.org/sd/principle.asp

[25] The Precautionary Principle; available online at: http://www.monitor.net/rachel/r586.html

[26] The Earth Charter Principles; available online at: http://www.earthcharter.org/earthcharter/charter.htm

[27] The Natural Step System Conditions; available online at: http://www.naturalstep.org/framework/framework_conditions.html

[28] The Daly Principles; available online at: http://www.wsu.edu:8080/ susdev/Daly90.html

[29] The Ceres Principles; available online at: http://www.ceres.org/our_work/principles.htm

[30] The Bellagio Principles; available online at: http://iisd1.iisd.ca/measure/bellagio1.htm

[31] The Ahwahnee Principles; available online at: http://www.lgc.org/ahwahnee/principles.html

[32] The Interface Steps To Sustainability; available online at: http://www.interfaceinc.com/us/company/sustainability/seven_steps.asp

[33] The Hannover Principles; available online at: http://www.mcdonough.com/principles.pdf 
[34] Anastas, Paul, and Zimmerman, Julie (2003). "Design through the 12 Principles of Green Engineering," Environmental Science \& Technology, March 1, 2003

[35] Vanegas, J., Pearce, A., and Bosch, S. (2002) "Built environment sustainability: An integrated approach to education, research, and outreach," Proceedings of the Conference on Engineering Education in Sustainable Development, Delft University of Technology, Delft, The Netherlands, October $24-25$, 2002, pp. 385-395 (paper in conference CD ROM)

[36] Vanegas, J., Pearce, A., and Bosch, S. (2002) "An engineering undergraduate/graduate course on sustainable design and construction," Proceedings of the Conference on Engineering Education in Sustainable Development, Delft University of Technology, Delft, The Netherlands, October $24-25$, 2002, pp. 396-407 (paper in conference CD ROM) 